\title{
Sleep-State Dependent Alterations in Brain Functional Connectivity under Urethane Anesthesia in a Rat Model of Early-Stage Parkinson's Disease
}

\author{
(1DEkaterina Zhurakovskaya, ${ }^{{ }^{*}}$ Juuso Leikas, ${ }^{2 "}$ Tiina Pirttimäki, ${ }^{1}$ Francesc Casas Mon, ${ }^{2}$ Mikko Gynther, ${ }^{2}$ \\ Rubin Aliev, ${ }^{3,4}$ Tomi Rantamäki, ${ }^{5}$ Heikki Tanila, ${ }^{1}$ Markus M. Forsberg, ${ }^{2}$ Olli Gröhn, ${ }^{1}$ Jaakko Paasonen, ${ }^{1}$ \\ and ${ }^{\circledR}$ Aaro J. Jalkanen ${ }^{\dagger}$
}

https://doi.org/10.1523/ENEURO.0456-18.2019

\begin{abstract}
${ }^{1}$ A. I. Virtanen Institute for Molecular Sciences, University of Eastern Finland, Kuopio, Fl-70211, Finland, ${ }^{2}$ School of Pharmacy, University of Eastern Finland, Kuopio, Fl-70211, Finland, ${ }^{3}$ Moscow Institute of Physics and Technology, 117303, Moscow, Russia, ${ }^{4}$ Institute of Theoretical and Experimental Biophysics, 142292, Puschino, Russia, and ${ }^{5}$ Laboratory of Neurotherapeutics, Division of Pharmacology and Pharmacotherapeutics, Faculty of Pharmacy, University of Helsinki, Helsinki, FI-00790, Finland
\end{abstract}

\begin{abstract}
Parkinson's disease (PD) is characterized by the gradual degeneration of dopaminergic neurons in the substantia nigra, leading to striatal dopamine depletion. A partial unilateral striatal 6-hydroxydopamine (6-OHDA) lesion causes $40-60 \%$ dopamine depletion in the lesioned rat striatum, modeling the early stage of PD. In this study, we explored the connectivity between the brain regions in partially 6-OHDA lesioned male Wistar rats under urethane anesthesia using functional magnetic resonance imaging (fMRI) at 5 weeks after the 6-OHDA infusion. Under urethane anesthesia, the brain fluctuates between the two states, resembling rapid eye movement (REM) and non-REM sleep states. We observed clear urethane-induced sleep-like states in 8/19 lesioned animals and $8 / 18$ control animals. 6-OHDA lesioned animals exhibited significantly lower functional connectivity between the brain regions. However, we observed these differences only during the REM-like sleep state, suggesting the involvement of the nigrostriatal dopaminergic pathway in REM sleep regulation. Corticocortical and corticostriatal connections were decreased in both hemispheres, reflecting the global effect of the lesion. Overall, this study describes a promising model to study PD-related sleep disorders in rats using fMRI.
\end{abstract}

Key words: 6-OHDA lesion; connectivity; rat; resting-state fMRl; sleep; urethane

\section{Significance Statement}

Disturbances in sleep patterns and rapid eye movement (REM) sleep behavior disorder are among the first symptoms of Parkinson's disease (PD). However, PD-related sleep disorders have been virtually unexplored in animal models. This is a first study which has examined the functional connectivity (FC) during urethane-induced sleep-like states in the partial striatal 6-OHDA lesion rat model of early-stage PD using functional magnetic resonance imaging (fMRI). We found that FC is significantly decreased in 6-OHDA lesioned animals, but only during the REM-like state. These changes affected both the lesioned and intact hemispheres, mostly involving corticocortical and corticostriatal connections. The results suggest that this rat model is a promising tool for studying sleep disturbances in early-stage PD with resting-state fMRI. 


\section{Introduction}

Parkinson's disease (PD) is the second most common neurodegenerative disease and the most common movement disorder affecting $1 \%$ of the population worldwide after the age of 70 years (Pringsheim et al., 2014). A gradual degeneration and loss of dopaminergic neurons in the midbrain substantia nigra pars compacta are the pathologic hallmarks leading to striatal dopamine (DA) depletion, resulting in progressive motor symptoms including bradykinesia, rigidity, and resting tremor, which are characteristic of PD (Schapira, 2009). In addition to the motor symptoms, PD patients suffer from a variety of non-motor symptoms, including sleep disorders, olfactory dysfunction, pain, depression, anxiety, impulsive behavior, and cognitive impairment, which significantly impact negatively on the patient's quality of life (Titova and Chaudhuri, 2017).

PD patients may experience a variety of sleep disorders, such as restless legs syndrome, rapid eye movement (REM) sleep behavior disorder (RBD), sleep fragmentation, and insomnia (French and Muthusamy, 2016). Because sleep disorders appear several years before the appearance of the motor deficits (Bargiotas et al., 2016), they have been considered as an early marker for PD. In particular, the presence of RBD represents a considerably elevated risk of developing PD (Postuma et al., 2013). PD patients with RBD have increased $\alpha$-synuclein deposition (Postuma et al., 2015), more severe initial motor symptoms, and they require higher levodopa doses as the disease progresses (Chung et al., 2017). It is notable that alterations in brain network organizations have been associated with RBD even before the onset of obvious motor impairment in PD (Ellmore et al., 2013). Thus, an experimental model mimicking early sleep disorders is needed in assessing potential treatments for these disorders and it may also represent a new approach for testing novel diseasemodifying treatments for early-stage PD.

Received November 20, 2018; accepted January 15, 2019; First published February 13, 2019.

The authors declare no competing financial interests.

E.Z., J.L., T.P., M.M.F., O.G., J.P., and A.J.J. designed research; E.Z., J.L., F.C.M., M.G., J.P., and A.J.J. performed research; E.Z., J.L., M.G., J.P., and A.J.J. analyzed data; E.Z., J.L., T.P., M.G., R.A., T.R., H.T., M.M.F., O.G., J.P., and A.J.J. wrote the paper.

This work was supported by Emil Aaltonen foundation (T.P.), Finnish Academy of Science and Letters (E.Z.), and the Academy of Finland (O.G.). The funding sources had no role in study design; in the collection, analysis and interpretation of data; in the writing of the report; or in the decision to submit the article for publication. We thank Kalle Voutilainen for help with the animal experiments and DA assay, Maarit Pulkkinen for technical assistance in fMRI experiments, Jaana Leskinen for help with biochemical assays, Raimo Salo for valuable advice in data analysis, and Dr. Ewen MacDonald for the linguistic revision of this paper.

${ }^{*}$ E.Z. and J.L. contributed equally to this work.

†J.P. and A.J.J. contributed equally to this work as co-senior authors.

Correspondence should be addressed to Aaro J. Jalkanen at Aaro.Jalkanen@uef.fi.

https://doi.org/10.1523/ENEURO.0456-18.2019

Copyright (C) 2019 Zhurakovskaya et al.

This is an open-access article distributed under the terms of the Creative Commons Attribution 4.0 International license, which permits unrestricted use, distribution and reproduction in any medium provided that the original work is properly attributed.
Unilateral lesioning of the substantia nigra dopaminergic neurons using the 6-hydroxydopamine (6-OHDA) is one of the most widely used animal models of PD (Bové and Perier, 2012). This lesion induces a gradual degeneration of nigrostriatal DA neurons and motor impairments resembling $P D$ phenotypes. Depending on the administration protocol and infusion site of the toxin, a 6-OHDA lesion can produce very different degree of biochemical and behavioral outcomes. A near complete loss of striatal DA can be induced by infusing the toxin into the medial forebrain bundle (MFB) or directly into the substantia nigra (Lee et al., 1996; Yuan et al., 2005). This procedure leads to prominent neurodegeneration and severe motor deficits. Instead, an intrastriatal infusion of 6-OHDA produces a partial striatal DA depletion (usually a 20-80\% DA deficiency depending on the 6-OHDA dose and number of infusion sites) accompanied by mild but progressive well characterized motor deficits (Sauer and Oertel, 1994; Przedbroski et al., 1995; Leikas et al., 2017). Thus, this partial 6-OHDA lesion is considered more relevant as a model for early-stage PD. Despite the relevance of sleep disturbances in early PD, the effects of the partial striatal 6-OHDA lesion on brain connectivity and sleep have not been well characterized. For example, it is not known whether the 6-OHDA lesioned rats express disturbances in brain activity during sleep resembling those encountered in PD patients.

Resting-state functional magnetic resonance imaging (rsfMRI) is a sophisticated MRI technique assessing functional connectivity (FC). It is typically based on the detection of correlating spontaneous low-frequency $(<0.1 \mathrm{~Hz})$ fluctuations in blood oxygenation level-dependent (BOLD) signals (Biswal et al., 1995); similar BOLD signal fluctuation profiles in different brain regions reflect synchronized neuronal activity and FC. It has proven its clinical value as a non-invasive imaging method for assessing disruptions in functional brain networks in patients with early and advanced PD (Nandhagopal et al., 2008; Lopes et al., 2016; Tahmasian et al., 2017).

Here, we used a unilateral partial striatal 6-OHDA lesion protocol producing $\sim 50 \%$ striatal DA depletion and investigated the functional brain network alterations in this rat model of early-stage PD by subjecting the animals to rsfMRI at 5 weeks after the 6-OHDA infusion. In particular, we focused on analyzing different urethane-induced sleeplike states (Clement et al., 2008; Wilson and Yan, 2010; Pagliardini et al., 2013) and based on the RBD symptomatology, we hypothesized that the potential brain connectivity changes would become manifest during the REM state of sleep. Furthermore, we measured the striatal levels of DA, GABA, and glutamate, the key neurotransmitters controlling the basal ganglia-thalamocortical motor network impaired in PD, to detect biochemical associations with the functional brain network alterations.

\section{Materials and Methods}

\section{Animals}

The study was conducted in twenty 6-OHDA lesioned, 10 sham-operated, and 10 naïve male Wistar rats supplied by the Laboratory Animal Center of the University of 
Eastern Finland (Kuopio, Finland). The rats were 8 weeks old and weighed 270-360 g at the beginning of the experiments. Unless otherwise stated, the rats were pairhoused in stainless steel cages and kept on a $12 \mathrm{~h}$ light/dark cycle (lights on at 07:00 A.M.) at an ambient temperature of $22 \pm 1{ }^{\circ} \mathrm{C}$. Pelleted food (Teklad 2016S, Harlan Laboratories) and tap water were available $\mathrm{ad}$ libitum. All procedures were made in compliance with ARRIVE guidelines and the European Commission Directive 2010/63/EU and were approved by the Finnish National Animal Experiment Board (licenses ESAVI-2014701, ESAVI-2013-00833). All effort was taken to minimize the number of animals used and their suffering.

\section{Drugs}

6-OHDA.HCl (Sigma-Aldrich) was dissolved in vehicle $(0.9 \% \mathrm{NaCl}$ containing $0.2 \mathrm{mg} / \mathrm{ml}$ ascorbic acid). Pentobarbital (Mebunat vet, Orion Oyj) and buprenorphine (Schering-Plow) were dissolved in saline, and urethane (Sigma-Aldrich) in sterile water. Lidocaine (Xylocaine) was obtained from AstraZeneca. The doses of drugs refer to the free bases.

\section{Partial unilateral 6-OHDA lesion model of early-stage PD}

The rats were anesthetized with pentobarbital $(55 \mathrm{mg} /$ $\mathrm{kg}$, i.p.). Lidocaine was applied to the scalp and to the surface of the skull and a single dose of buprenorphine $(0.02 \mathrm{mg} / \mathrm{kg}$, s.c.) was given to relieve any postoperative pain. Then, 6-OHDA (10 $\mu \mathrm{g} / 4 \mu \mathrm{l}, n=20)$ or vehicle (i.e., sham lesion, $n=10$ ) was infused into the right striatum (coordinates from bregma: AP: +1.0, L: -2.7 , DV: -5.0 ; Paxinos and Watson, 2007) at a flow rate of $0.5 \mu \mathrm{l} / \mathrm{min}$. The needle was retained in position for $4 \mathrm{~min}$ after the infusion to prevent backflow. After the surgery, the animals were kept in individual stainless steel cages for $3 \mathrm{~d}$ to allow recovery and subsequently returned in groups of two. The success of the lesion was verified by striatal DA analysis after rsfMRI imaging. Two animals were excluded from the study based on an abnormal striatal DA ratio: (1) no DA depletion was observed in lesioned striatum indicating a failed 6-OHDA administration (lesion/intact DA ratio $>13 \times$ SEM vs group mean), and (2) an abnormal decrease in striatal DA ratio was observed in one sham lesioned rat (lesion/intact DA ratio $<6 \times$ SEM vs group mean). One 6-OHDA lesioned animal was excluded from the study because of an abnormal finding in the anatomic MRI image (possible cyst or effusion). Furthermore, one sham lesioned animal was excluded from the biochemical data analysis because of an error occurring during tissue sample preparation.

\section{fMRI}

fMRI was done with 7T Bruker Pharmascan MRI system (Bruker Biospin) 5 weeks after 6-OHDA or sham lesion when the rats were 13 weeks old. Naïve animals were imaged in the beginning of the experiments at 8 weeks of age. A rat brain surface and a resonator volume coil were used for signal reception and transmission, respectively (both quadrature coils from Bruker Biospin). Rats were anesthetized with urethane (1250-1500 mg/kg, i.p.), and subsequently fixed to an MRI rat holder with ear bars and a bite bar. The rsfMRI data were acquired with single-shot spin-echo echoplanar imaging sequence with the following parameters: repetition time: $2000 \mathrm{~ms}$, echo time: 45 $\mathrm{ms}, 1200$ volumes (40 min), field-of-view: $32 \times 32 \mathrm{~mm}, 17$ slices with a thickness of $0.9 \mathrm{~mm}$, matrix size $64 \times 64$, and bandwidth $200 \mathrm{kHz}$.

An MRI-compatible small animal monitoring system (Model 1025, Small Animal Instruments), including rectal temperature probe, respiration pneumatic sensor, and fiber-optic oximetry sensor, was used to monitor animal physiology. The rats were kept warm $\left(\sim 37^{\circ} \mathrm{C}\right)$ by a built-in water circulation system (ThermoFisher Scientific).

Before the analyses, the rsfMRI data were converted to NIfTI using in house written MATLAB code (http://aedes.uef.fi), slice-timing corrected, motion-corrected, spatially smoothed $(2 \times 2$ voxel full-width at half-maximum Gaussian kernel), and coregistered by using SPM8 (www.fil.ion.ucl.ac.uk/spm) and MATLAB v2017b (MathWorks). The FC analyses were done with an in-house MATLAB code, Aedes, and SPM8. Seventeen regions-of-interest (ROIs) were drawn according to an anatomic atlas (Paxinos and Watson, 2007; Fig. 1). Subsequently, the rsfMRI data were bandpass filtered at $0.01-0.08 \mathrm{~Hz}$ to minimize physiologic and hardware-induced noise.

To obtain measures for FC, partial correlation coefficients between ROls (or ROI and voxels in correlation maps) were calculated by using MATLAB. All six motion correction parameters, obtained with SPM, were used as regressors in the correlation calculations to minimize the effect of motion on the results.

\section{Assessment of sleep states and FC}

Fluctuations in breathing rate during $\mathrm{fMRI}$ were used as indirect measures to detect spontaneous sleep-like states as described by (Wilson et al., 2011; Pagliardini et al., 2012). States with high and low breathing rates were manually labeled as REM-like and non-REM (NREM)-like sleep states, respectively. Animals with transitions between NREM-like and REM-like state were included in the sleep-state analysis. The state-labeled fMRI data were divided into windows of size of 30 volumes. State-labeled partial correlation coefficients were calculated for each window, and subsequently averaged within each subject. If an animal did not have at least $90 \mathrm{fMRI}$ volumes of sleep-like state in total, it was excluded from the sleepstate analysis.

\section{Dissection of brain samples and biochemical analyses}

6-OHDA and sham lesioned animals were killed by decapitation under urethane anesthesia immediately after the rsfMRI measurements. After decapitation, the brains were rapidly removed and both striata were dissected on ice, frozen, and stored at $-80^{\circ} \mathrm{C}$ until analyzed. The striatal samples were homogenized (Soniprep 150 MSE Scientific Instruments) in 25 volumes of ice-cold $0.1 \mathrm{M}$ perchloric acid (Merck KGaA). The homogenates were centrifuged at $15000 \times g\left(4^{\circ} \mathrm{C}, 15 \mathrm{~min}\right.$, Heraeus Sepatech, Biofuge 17RS). The supernatant was collected and filtered (GHP Acrodisc 13, $0.45 \mu \mathrm{m}$ ) into Eppendorf tubes. Super- 

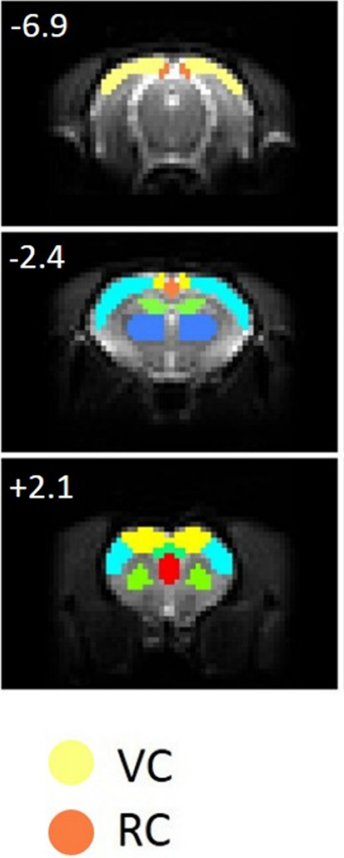
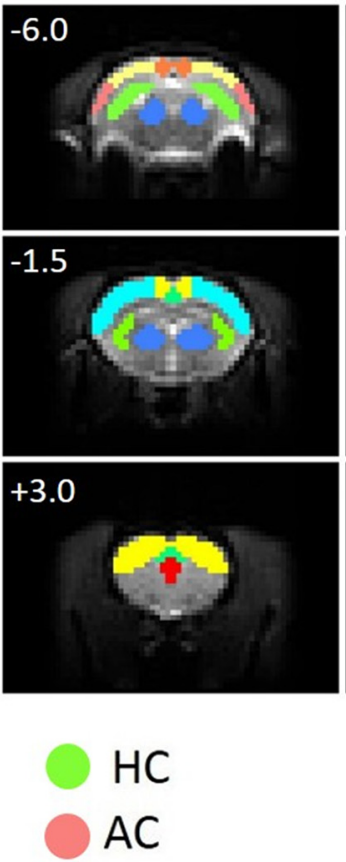
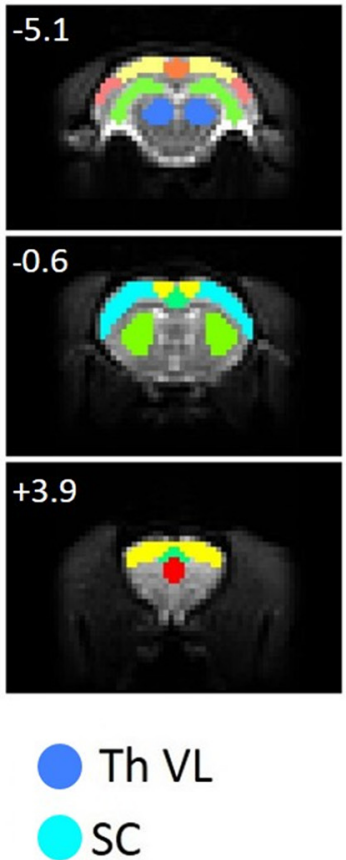
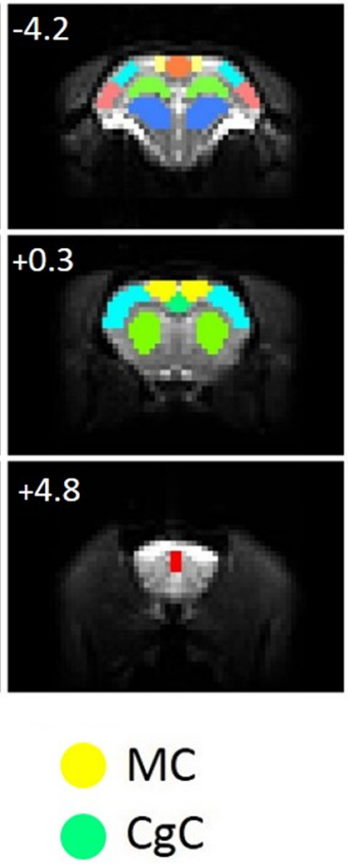
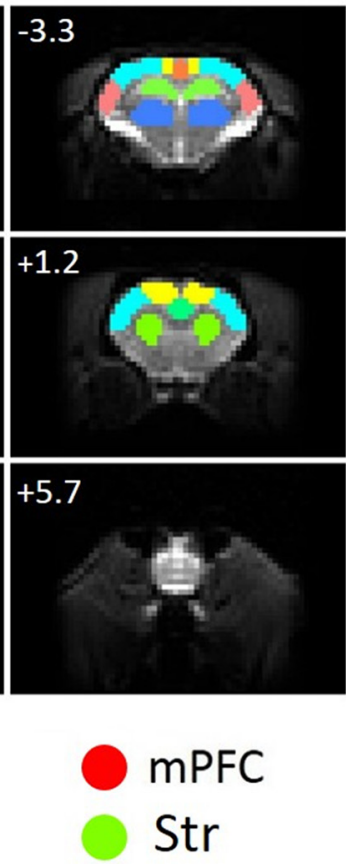

Figure $1 \mathrm{ROIs}$ used for FC analysis. ROls are overlaid on original spin-echo echoplanar imaging functional MRI images. AC, Auditory cortex; $\mathrm{CgC}$, cingulate cortex; HC, hippocampus; MC, motor cortex; mPFC, medial prefrontal cortex; RC, retrosplenial cortex; SC, somatosensory cortex; Str, striatum; Th VL, ventral lateral thalamus; VC, visual cortex. Distance to bregma in millimeters is marked in the top left corner of each slice.

natants were further diluted twofold with $0.1 \mathrm{~m}$ perchloric acid before DA analysis and 350-fold with acetonitrile (CAN; Mallinckrodt Baker) before GABA and glutamate analysis. DA levels in both striata were analyzed by a high performance liquid chromatography method with electrochemical detection (Kääriäinen et al., 2008). Striatal GABA and glutamate levels were measured with a liquid chromatography/mass spectrometry (LC-MS/MS) method. Liquid chromatography was performed on Agilent 1290 Infinity LC (Agilent Technologies) instrumentation. GABA and glutamate were separated using Waters Acquity UPLC BEH amide column $(100 \times 2.1 \mathrm{~mm}, 1.7 \mu \mathrm{m})$. The column temperature was maintained at $40^{\circ} \mathrm{C}$. The A mobile phase was $40 \mathrm{~mm}$ ammonium formate buffer + ACN (1:1) and the $B$ mobile phase was $200 \mathrm{~mm}$ ammonium formate buffer + ACN (1:10). A gradient was applied for over 12 min as follows: from 0 to 6 min $95-70 \%$ B, from 6 to $7 \mathrm{~min}, 70-95 \% \mathrm{~B}$, and finally the column was equilibrated from 7 to $12 \mathrm{~min}$ at $95 \%$. The flow rate was 0.3 $\mathrm{ml} / \mathrm{min}$ and the injection volume was $5 \mu \mathrm{l}$. The LC-MS/MS data were acquired with an Agilent 6410 Triple Quadrupole Mass Spectrometer (Agilent Technologies) using Multiple Reaction Monitoring applying the following conditions: electrospray ionization, positive ion mode; drying gas (nitrogen) temperature, $200^{\circ} \mathrm{C}$; drying gas flow rate, $16 \mathrm{~L} / \mathrm{min}$; nebulizer pressure, $25 \mathrm{psi}$; and capillary voltage, 4500 V. Quantitative transitions were $104 \rightarrow 87$ and 148 $\rightarrow 130(\mathrm{~m} / \mathrm{z})$ for GABA and glutamate, respectively. The fragmentor energy was $380 \mathrm{~V}$ and collision energy was 7 $\checkmark$ for both GABA and glutamate. Biochemical analyses were not performed on the naïve animals.
Striatal DA, GABA, and glutamate ratios were calculated with the equation $C_{\text {lesioned side }} / C_{\text {intact side. }}$.

\section{Statistical analysis}

All results are expressed as mean $\pm S D$. Differences in DA, GABA, and glutamate levels in lesioned versus intact striatum were tested with two-tailed paired $t$ test using GraphPad Prism 5.03 software. The physiologic parameters were compared between groups using one-way ANOVA with Tukey's multiple-comparison test with GraphPad Prism software. The comparison of sleep-like states durations was done using two-tailed unpaired $t$ test with in-house MATLAB codes. The correlation coefficients were normalized with Fisher's $z$-transformation. The group comparison for ROI-based and seed-based analysis were performed using two-tailed unpaired $t$ test with false discovery rate (FDR) correction for multiple comparisons with in-house MATLAB codes. The criterion for statistical significance was set at $p<0.05$ for all tests.

\section{Results}

The effect of the partial striatal 6-OHDA lesion on striatal levels of dopamine, GABA, and glutamate

The effects of 6-OHDA and sham lesions on striatal levels of biochemical markers are shown in Figure 2. As expected, the partial striatal 6-OHDA lesion $(n=18)$ depleted striatal DA levels by $51 \%$ in the lesioned side $(33.2 \pm 10.5$ vs $67.9 \pm 9.0 \mathrm{nmol} / \mathrm{g}$ of tissue weight in lesioned and intact striatum, respectively; paired $t$ test, $p$ $<0.0001$ ). Additionally, the 6-OHDA lesion induced a slight but significant increase in striatal GABA levels $(23.1 \pm 2.0$ vs $22.5 \pm 1.4 \mu \mathrm{mol} / \mathrm{g}$ of tissue weight in le- 

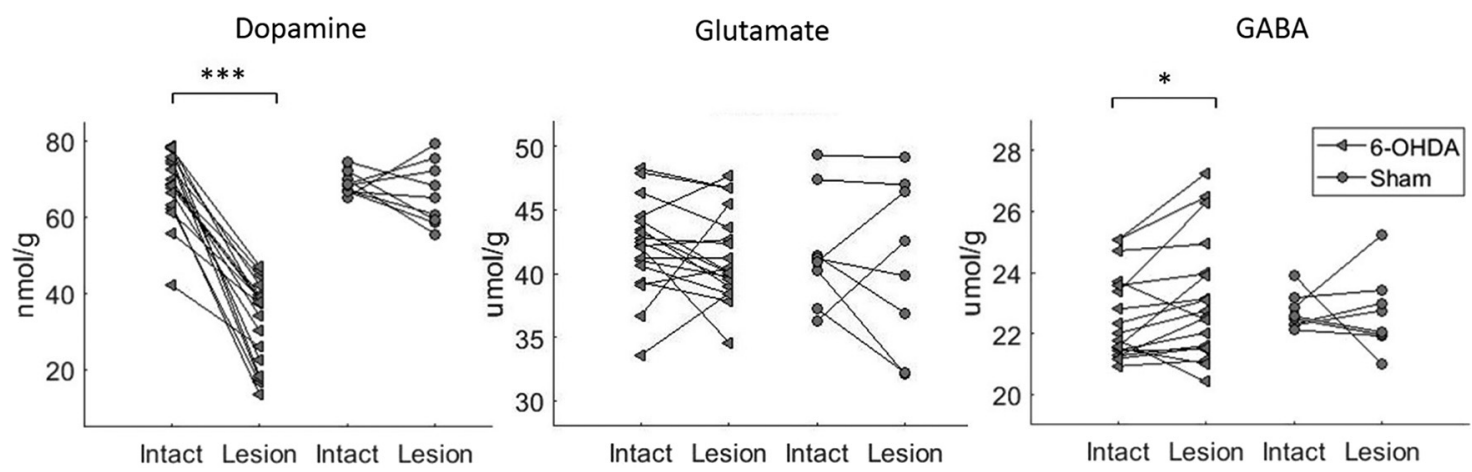

Figure 2 Dopamine (nmol/g tissue), glutamate, and GABA levels ( $\mu \mathrm{mol} / \mathrm{g}$ tissue) in the intact and lesioned striatum in 6-OHDA lesioned and sham animals. Paired $t$ test: $* p<0.05, * * * p<0.001$.

sioned and intact striatum, respectively; paired $t$ test, $p<$ 0.05 ). In contrast, the 6-OHDA lesion had no effect on striatal glutamate levels $(41.4 \pm 3.4$ vs $42.2 \pm 3.5 \mu \mathrm{mol} / \mathrm{g}$ of tissue weight in lesioned and intact striatum, respectively). The sham lesion $(n=8)$ exerted no significant effect on striatal DA $(64.4 \pm 7.1$ and $69.3 \pm 2.8 \mathrm{nmol} / \mathrm{g}$ of tissue weight in sham-lesioned and intact striatum, respectively, n.s.), GABA ( $22.7 \pm 1.3$ vs $22.7 \pm 0.6 \mu \mathrm{mol} / \mathrm{g}$ of tissue weight in sham-lesioned and intact striatum, respectively, n.s.) or glutamate $(40.8 \pm 6.2$ vs $41.7 \pm 4.2$ $\mu \mathrm{mol} / \mathrm{g}$ of tissue weight in lesioned and intact striatum, respectively, n.s.) levels.

\section{Animal physiology during fMRI measurements}

There were no statistical differences between the 6 -OHDA and sham lesioned animals in any of the physiologic measures [breathing rate $(125 \pm 21$ vs $128 \pm 19$, breaths/min, sham vs $6-$ OHDA, respectively), heart rate (358 \pm 32 vs $380 \pm 37$ beats $/ \mathrm{min}$ ), core body temperature $\left(37.1 \pm 0.4\right.$ vs $\left.37.0 \pm 0.5^{\circ} \mathrm{C}\right)$, and weight $(418 \pm 25$ vs 412 $\pm 29 \times g)$ ] during the onset of the fMRI measurement. In the naïve group, the corresponding physiologic parameters were as follows: breathing rate $107 \pm 12$ breaths/min, heart rate $349 \pm 39$, temperature $36.7 \pm 0.6^{\circ} \mathrm{C}$, and weight $316 \pm 22 \mathrm{~g}$, i.e. naiive animals had lower weights and also a lower breathing rate than those of lesioned and sham animals (both parameters $p<0.05$, one-way ANOVA with Tukey's test), but all parameters are within the normal range.

\section{The effects of the unilateral partial striatal 6-OHDA lesion on overall connectivity}

First, we investigated whether the sham lesion would affect the FC by comparing the region-region connectivity of the sham group to that of the naïve animals. Although there were some weight and breathing differences between the sham and naïve animals, there were no differences in the resting-state $\mathrm{FC}$ (all $p$ values $>0.2$, unpaired $t$ test, FDR-corrected; Fig. $3 A$ ), evidence of the robustness of the urethane-induced REM/NREM-like FC states. Because the sham lesion had no effect on the striatal biochemical markers nor the resting-state FC, we combined the naïve and sham groups and refer to it as the control group $(n=18)$ from here onward.
Next, we compared the resting-state FC obtained from the whole fMRI measurement period between the 6-OHDA lesioned and control groups. This analysis revealed no significant differences in FC between the $6-O H D A$ lesioned and control animals in overall connectivity; only trends toward increased $\mathrm{FC}$ from the right to the left ventral lateral thalamus $(p=0.048$, not FDRcorrected) and from the right ventral lateral thalamus to the cingulate cortex ( $p=0.040$, not FDR-corrected) were observed. In addition, there was a trend toward decreased FC from ipsilateral to contralateral striatum $(p=$ 0.047, not FDR-corrected). After correction for multiple comparisons, however, these trends become nonsignificant.

\section{FC during different sleep states}

The fact that REM sleep is more active and energydemanding state (Steriade and Hobson, 1976; Franzini, 1992; Lenzi et al., 2000) than NREM sleep and the proposition that REM-sleep associated sleep disorders are early symptoms of progressive neurodegeneration in $\mathrm{PD}$ patients (Heller et al., 2017) prompted us to separate REM and NREM sleep-like states in our rsfMRI analysis. Based on the breathing rate fluctuations (Wilson et al., 2011), we observed clear state changes between REM-like and NREM-like state in 8/19 control animals and 8/18 lesion animals. In the rest of the animals, only one sleep state was observed, and they were excluded from the sleepstate FC analysis. The lack of sleep-state transitions in approximately one-half of the animals may be explained by differences in the depth of anesthesia (Gretenkord et al., 2016) or factors influencing respiratory function, such as the environmental temperature (Whitten et al., 2009) or inhaled oxygen (Pagliardini et al., 2013; Hauer et al., 2018). The average durations for the REM-like and NREM-like states were $99 \pm 80.4$ and $78.6 \pm 70.8 \mathrm{~s}$, respectively. There were no significant differences in state durations between control and 6-OHDA lesioned animals ( $p=0.96$ for REM-like states, $p=0.84$ for NREM-like states, unpaired $t$ test).

The FC differences between REM-like and NREM-like states in the control group had the same pattern as displayed by healthy rats in a previous study (Zhurakovskaya et al., 2016): increased thalamocortical connectivity 
A
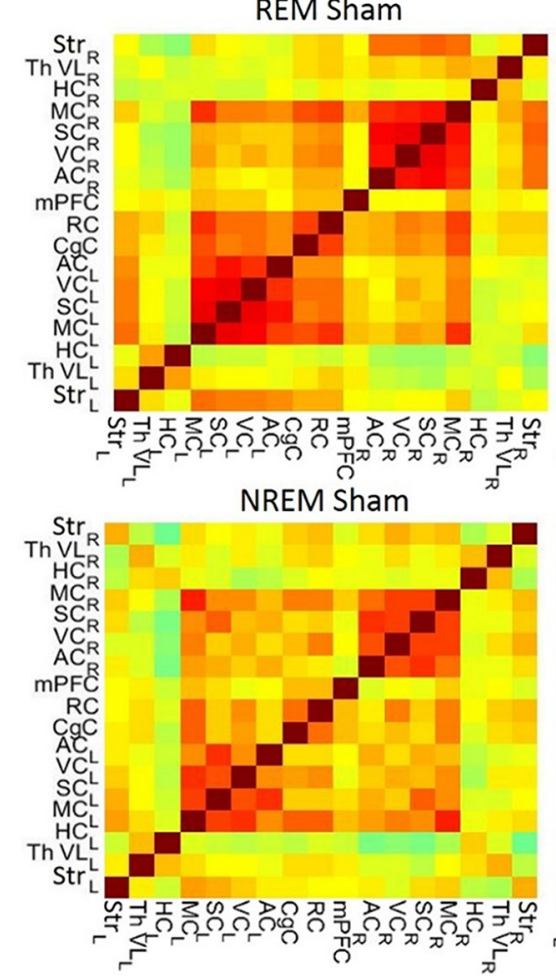

B
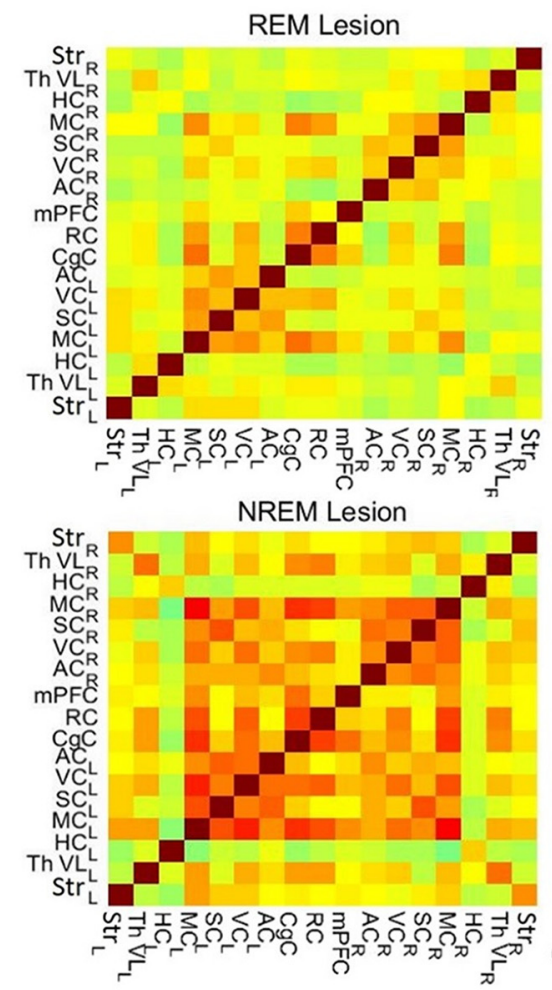

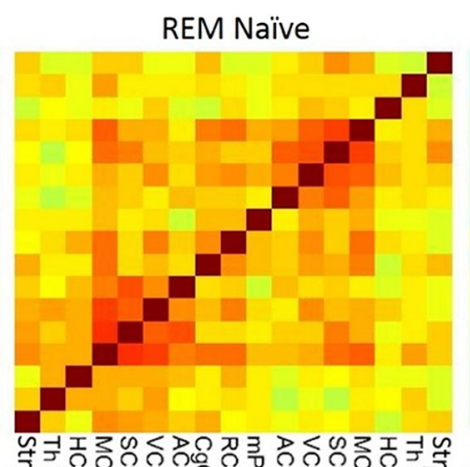

REM Naïve

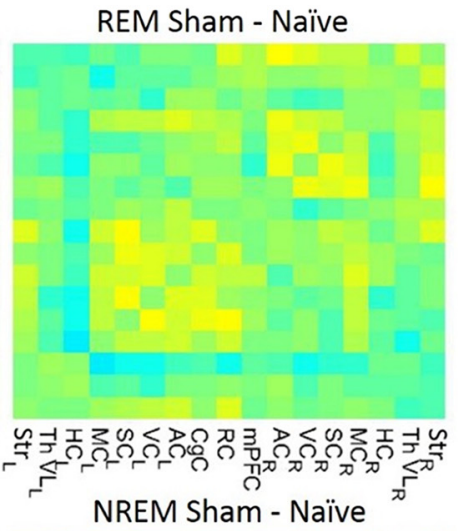

NREM Naïve
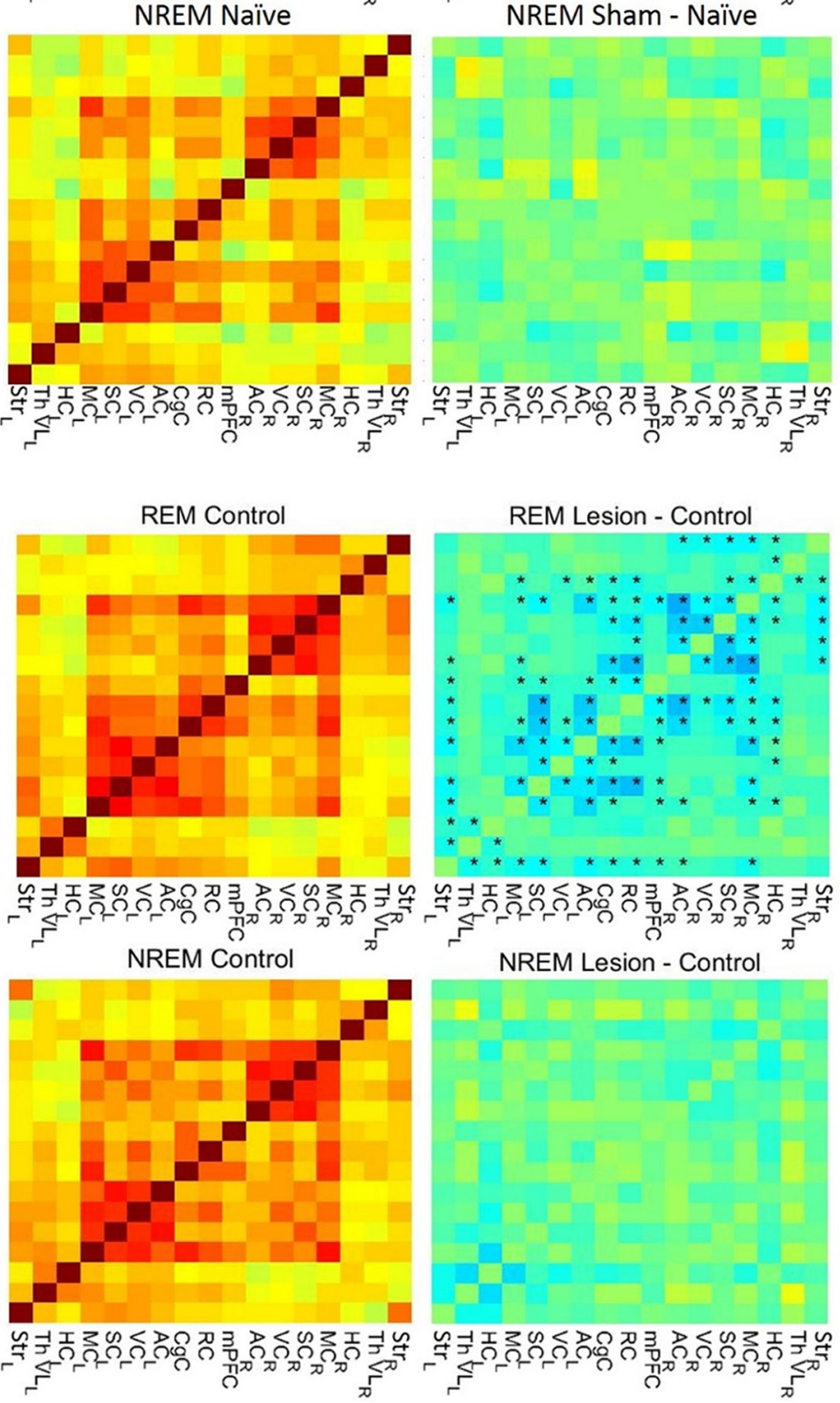

Figure 3 FC between the brain regions in naïve and sham animals $(\boldsymbol{A})$. There were no statistically significant differences after FDR correction for multiple comparisons between sham and naiive groups. FC between the brain regions in 6-OHDA and control animals (B). Top, Connectivity matrices for the REM-like state. Bottom, Connectivity matrices for the NREM-like state. Left to right, Mean connectivity matrix in 6-OHDA lesioned animals, mean connectivity matrix in control animals, the difference between the first two panels. A higher absolute correlation coefficient corresponds to higher connectivity between regions. In the difference pictures (top right), stars denote statistically significant differences between groups $(p<0.05$, FDR-corrected for multiple comparisons). Abbreviations for brain regions as in Figure 1. 


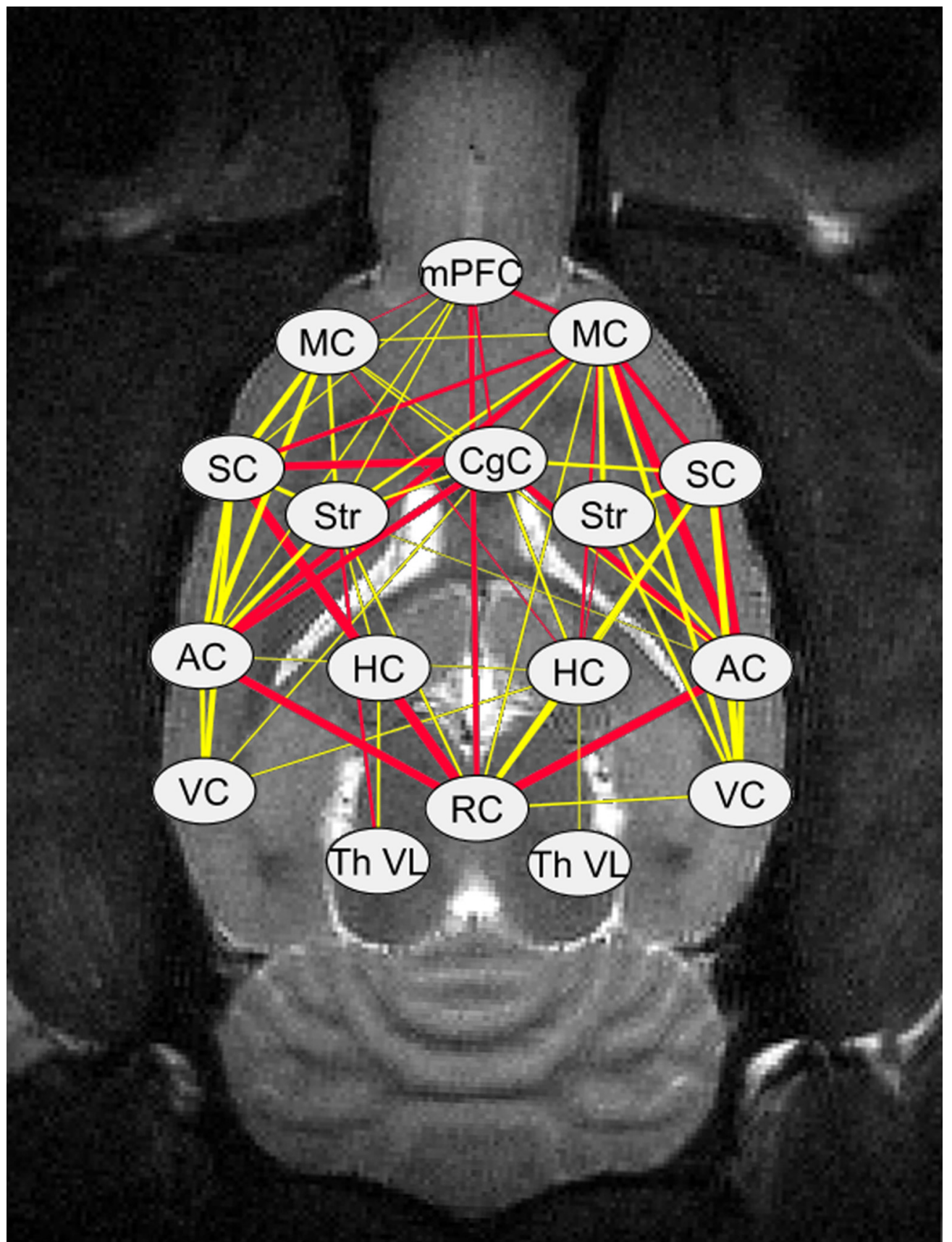

Figure 4 Significantly decreased ( $p<0.05$, FDR-corrected for multiple comparisons) connections between brain regions during REM-like state in rats with partial striatal 6-OHDA lesion. The width of the line corresponds to the mean correlation difference between control and lesioned groups: a thicker line represents a greater decrease in the correlation of the lesioned group. The differences in correlation coefficients range from 0.12 to 0.41 . Yellow lines represent $p$ values from 0.01 to 0.05 ; red lines, $p$ values $<0.01$. Abbreviations for brain regions as in Figure 1.

during REM-like state and increased corticocortical connectivity between hemispheres during the NREM-like state. However, FC was disturbed in partially 6-OHDA lesioned animals compared with control rats. Interestingly, these disturbances were strongly dependent on the sleep-like state (Fig. 3B). During the REM-like state, corticocortical, striatocortical and corticohippocampal connections were substantially decreased in 6-OHDA lesioned animals ( $p<0.05$, FDR corrected; Figs. 3B, 4). In contrast, during the NREM-like state, there were no differences in the FC between the control and lesioned animals (all $p$ values $>0.8$ ).

The seed-based voxelwise analyses, obtained from ipsilateral motor cortex and striatum (Fig. 5), illustrate the 6-OHDA-induced extensive striatocortical and subsequent corticocortical disruptions in FC during the REMlike sleep state. No differences were observed during the NREM-like state (data not shown). 
A

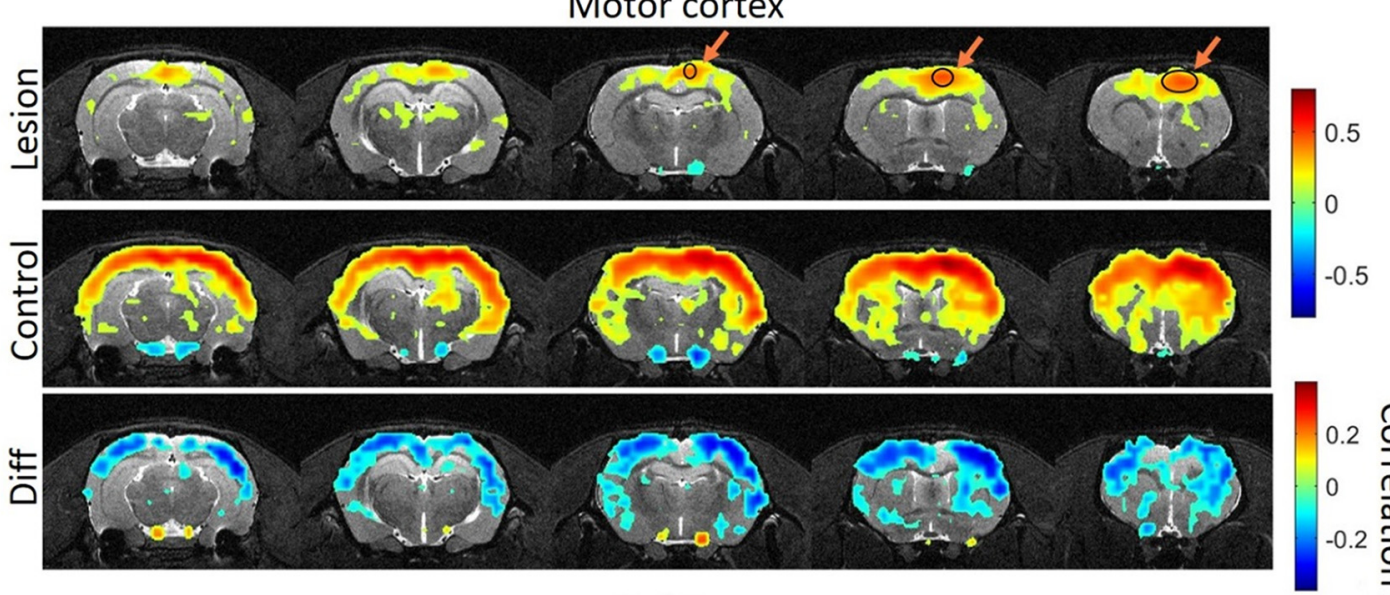

Motor cortex

A

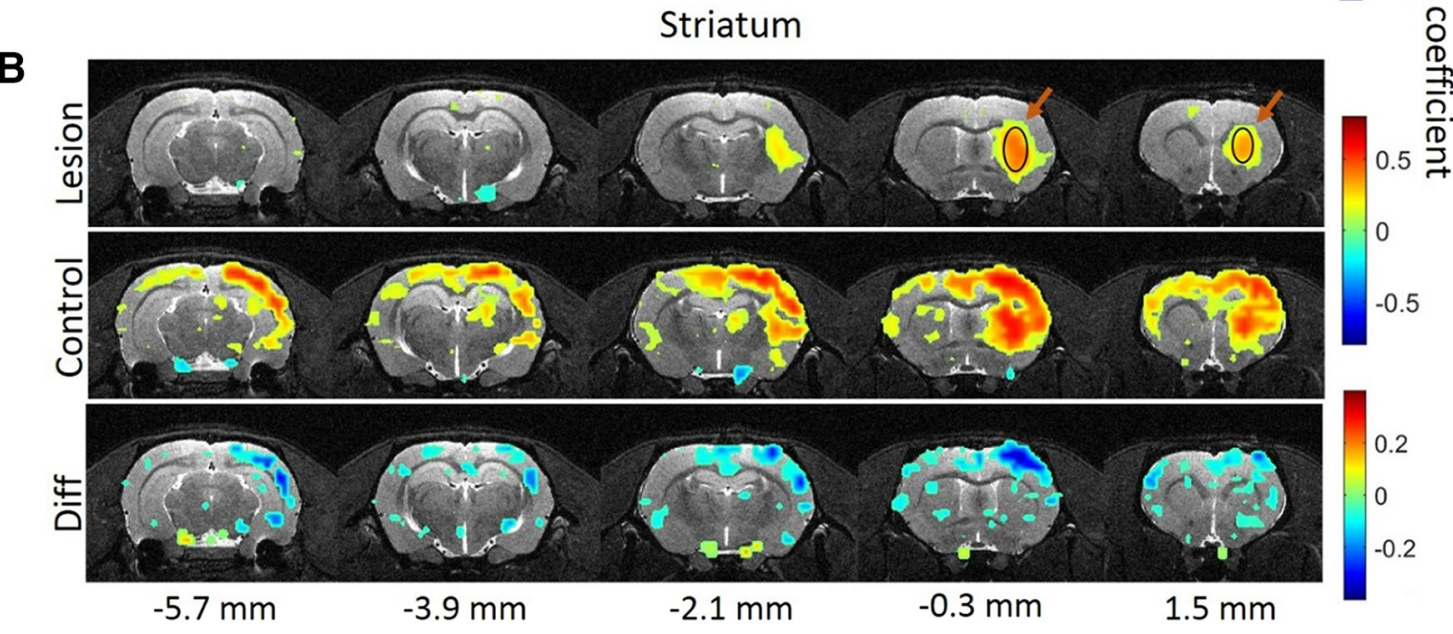

Figure $5 \mathrm{FC}$ maps during REM-like state with seed region in right motor cortex $(\boldsymbol{A})$ and right striatum $(\boldsymbol{B})$. Top row, Group connectivity map for lesioned animals (statistically different from 0 correlations, $p<0.05$, FDR-corrected for multiple comparisons); middle row, group connectivity map for control animals; bottom row, statistically significant differences $(p<0.05$, FDR-corrected for multiple comparisons) between the first two. The seed region is marked with arrows and circles in the group map of lesioned animals. Distance to bregma for each slice is marked at the bottom.

\section{Discussion}

Intrastriatal infusion of 6-OHDA produces a gradual degeneration of the nigrostriatal dopaminergic pathway and a partial DA depletion in the striatum accompanied with behavioral manifestations resembling early-stage PD. The behavioral outcomes of the partial 6-OHDA model have been thoroughly characterized (Sauer and Oertel, 1994; Przedbroski et al., 1995; Leikas et al., 2017), and here, we show that the partial striatal DA depletion induces sleep-state-dependent changes in FC between several brain regions during urethane-induced sleep.

The observed DA deficiency $(-51 \%) 5$ weeks after infusion of a single $10 \mu \mathrm{g}$ intrastriatal 6-OHDA dose is well in line with earlier studies using a similar 6-OHDA administration protocol (Lee et al., 1996; Leikas et al., 2017). Importantly, the extent of the striatal DA depletion in the present model is similar to that of the patients with an early clinically detectable PD (Schapira, 2009), highlighting the relevance of this model as an experimental model of early PD. In addition, 6-OHDA induced a small but significant increase in striatal GABA levels, which is in accordance with earlier studies in experimental models of
PD (Tanaka et al., 1986; Chassain et al., 2008), as well as with studies in PD patients using in vivo MRI (Emir et al., 2012) or postmortem tissue level GABA analysis (Kish et al., 1986). In contrast, the 6-OHDA lesion had no effect on striatal GLU levels, which is consistent with an earlier in vivo study conducted in 6-OHDA lesioned rats (Tanaka et al., 1986), and parallels studies in PD patients (TaylorRobinson et al., 1999; Kickler et al., 2007).

Our initial rsfMRI analysis on overall FC, obtained from the whole fMRI data, revealed only trends toward increased connectivity in some thalamocortical connections and between the ipsilateral and contralateral striatum. This result is in line with a very recent study in partially 6-OHDA lesioned rats showing a modest increase in FC in ipsi-lesioned and contra-lesioned regions of the corticobasal ganglia network at 3 weeks after the lesion (Perlbarg et al., 2018). The overall weaker changes in connectivity strengths observed in our study are most likely attributable to the smaller 6 -OHDA dose $(1 \times 10 \mu \mathrm{g}$ vs $2 \times 10 \mu \mathrm{g}$ ) resulting in a lower degree of nigrostriatal dopaminergic damage in our model. In addition, a few recent studies have shown FC changes occurring in rats 
receiving higher 6-OHDA dose producing a complete loss of striatal DA. As expected, the high degree of dopaminergic damage induced by an MFB lesion has more prominent effects on FC, as indicated by reduced FC between the striata and increased FC between the lesioned striatum and cortical areas in both hemispheres (Monnot et al., 2017), and by increased cross-hemispheric thalamic FC and a general reduction in connectivity in the ipsilateral hemisphere and especially in cortical areas (Westphal et al., 2017). These clear differences between the partial and full lesion models are most likely attributable to the different degree of nigrostriatal dopaminergic damage. Furthermore, more prominent compensatory mechanisms in the MFB model may play a role in these phenomena. These mechanisms include increased bursting activity of the subthalamic nuclei (Janssen et al., 2012) and activation of alternative motor pathways (Eckert et al., 2006; Mallol et al., 2007) that attempt to compensate for the absence of ipsilateral nigrostriatal DA in the MFB model. Altogether, the present study further supports the less severe nature of the partial 6-OHDA lesion model and its relevance as a model for early-stage PD.

The sleep disturbances associated with early PD stimulated us to investigate whether the partial striatal 6 -OHDA lesion rat model and urethane-induced sleep-like states could be a relevant approach for studying the pathophysiology of PD-related sleep disorders, particularly RBD, which have been considered as an early marker for PD because these sleep-related symptoms may appear even several years before the motor deficits (Postuma et al., 2013; Bargiotas et al., 2016). Sleep disorders are also associated with altered brain FC (Ellmore et al., 2013). Because natural sleep cannot be investigated with preclinical rsfMRI, recent studies have exploited different pharmacological tools to elicit sleep-like state (Wilson and Yan, 2010; Zhurakovskaya et al., 2016). Urethane anesthesia can be considered a practical model of natural sleep, because it is claimed to uniquely induce similar EEG and respiratory characteristics and sleep-like states as natural sleep in rodents. Additionally, urethane provides stable anesthesia for several hours with a normal physiologic state as reflected in the normal values of blood gases (Paasonen et al., 2016), while only minimally modulating multiple neurotransmitter systems, several brain regions, and autonomic functions (Maggi and Meli, 1986; Hara and Harris, 2002), making it an ideal anesthetic agent to be exploited in rsfMRI studies (Paasonen et al., 2018). Furthermore, the connectivity differences between states in urethane-anesthetized rats resemble the changes in the connectivity patterns occurring in natural sleep in humans (Zhurakovskaya et al., 2016).

In the present study, the sleep-like state rsfMRI connectivity patterns were similar in control animals as previously described in healthy rats under urethane anesthesia (Zhurakovskaya et al., 2016), indicating that these animals can serve as a valid control for detecting changes in connectivity patterns. We found that brain FC patterns differed between striatal 6-OHDA-lesioned and control rats, but the differences between the groups were significant only during the REM-like sleep state. During the
REM-like sleep, the 6-OHDA lesion caused extensive disturbances in FC in intracortical areas but also between the cortical areas and the striatum and hippocampus. Notably, reductions in FC occurred in both hemispheres suggesting that the unilateral striatal DA depletion significantly also disturbed interhemispheric connections during the REM-like sleep. The disruptions in striatocortical signaling are not surprising considering the key role of striatal DA in controlling the cortico-striato-thalamocortical motor circuitry; according to this classical basal ganglia circuitry model of PD, DA controls the release of GABA in striatum, and thus regulates the activity of the basal ganglia output nuclei. In PD, the striatal DA depletion causes increased GABAergic inhibitory control in thalamus leading to over-inhibition of the thalamocortical glutamatergic signaling, and finally, to motor dysfunction (Centonze et al., 1999; Blandini et al., 2000; DeLong and Wichmann, 2007). In support for the dopaminergic control of GABA release in striatum, we also observed a slight increase in striatal GABA levels in 6 -OHDA lesioned rats. The over-inhibition of the cortico-striato-thalamo-cortical circuitry could be reflected as reduced $\mathrm{FC}$ between the striatum and cortical areas. One could also speculate that the observed intracortical disruptions are a downstream consequence of the impaired striatocortical signaling.

It is noteworthy that we did not observe any significant 6-OHDA lesion-dependent changes in FC without differentiating between the different sleep-like states. Thus, it appears that the categorization of data based on sleeplike states improves the sensitivity of the rsfMRI analysis. The presence of the significantly impaired striatocortical connectivity only during the REM-like state could be explained by an overall decrease in cortical effective connectivity during the NREM-like state, which is partially restored during the REM-like state (Massimini et al., 2010). In other words, the silencing of long-range connectivity from cortex during the NREM state might hinder the observation of striatocortical connectivity changes. However, this explanation does not apply to the changes in corticocortical connectivity. Another possibility for the altered FC during different states of sleep is the direct participation of DA in the regulation of sleep. Striatal 6-OHDA injections induce retrograde dopaminergic cell death in substantia nigra pars compacta (Penttinen et al., 2016), and it is well established that a loss of these neurons disturbs the sleep patterns of rats (Lima et al., 2007), including changes in the regulation of muscle tone during REM sleep (Vo et al., 2014). This may be reflected in alterations in the connectivity between motor and somatosensory cortex and other cortical areas, as well as striatocortical connectivity during urethane-induced sleep.

It is interesting to note that the 6-OHDA-induced changes in FC were not restricted to the classical PDassociated cortico-striato-thalamo-cortical circuitry during the REM-like sleep. In particular, ipsilateral and contralateral hippocampal connections with the striatum, the cingulate cortex, and the ventral lateral thalamus were impaired by the striatal DA depletion. The disturbances in hippocampal connections may be associated with the 
well established memory impairing effects of the 6-OHDA lesion (More et al., 2016). It is unclear how striatal DA loss regulates hippocampal connections because there is no direct pathway connecting the dorsal striatum and hippocampus. However, FC may occur between any brain structures that are connected by large distributed networks. For instance, thalamus plays a central role in the complex network connecting the basal ganglia and cortical areas (Lanciego et al., 2012), and the hippocampus receives inputs from the thalamus. These excitatory inputs may well be affected by the increased GABAergic inhibitory control from the basal ganglia and explain the decreased hippocampal connectivity in 6-OHDA rats. Furthermore, the hippocampus has direct connections to the association cortex and to the entorhinal cortex, which has reciprocal projections to the cingulate cortex (Kerr et al., 2007). The cingulate cortex is further connected to wide cortical areas, and through this pathway, the hippocampus is also connected to many cortical areas. Therefore, it can be hypothesized that altered striatocortical connectivity could trigger disruptions in the balance of intracortical FC, which could be reflected as disturbances in corticohippocampal connectivity.

Non-invasive imaging and FC analysis are effective tools in the comparison of animal disease models and human pathology. In our study, the corticocortical and striatocortical connectivities were significantly decreased in 6-OHDA-lesioned animals during the REM-like sleep state. Decreased connectivity within the basal ganglia circuitry has been detected in patients with early stage PD (Szewczyk-Krolikowski et al., 2014; Dayan and Browner, 2017). Furthermore, the decreased FC from putamen to sensorimotor cortex and contralateral putamen has been observed already in an early stage of the disease (Luo et al., 2014). In patients with mid-stage and advanced stage of PD, decreased corticocortical and striatocortical connectivity has been reported in several studies (Hacker et al., 2012; Sharman et al., 2013). However, to confirm the translational value of the present results, the imaging should be conducted in conscious 6-OHDA lesioned animals. In addition, there is always variability in clinical studies in patients' disease severities, pharmacotherapies, and ages, which introduces uncontrollable dispersion to data and complicates the comparison between animal studies and clinical findings. Despite the obvious differences between species and challenges in data acquisition in rodent rsfMRI compared with human studies, intrastriatally administered 6-OHDA, i.e., producing $\sim 50 \%$ striatal DA depletion, appears to induce the FC changes resembling those present in PD patients. Hence, these findings improve the construct validity of the partial striatal 6-OHDA lesion model.

Rodents with various nigrostriatal 6-OHDA lesions have been reported to display similar disturbances in sleep architecture as observed in PD patients. For example, rats with unilateral MFB lesion encounter increased muscle activity and limb movements during REM sleep (Vo et al., 2014) resembling those in PD patients. Furthermore, rats with bilateral partial striatal 6-OHDA lesion spend more time awake and have more frequent sleep-state transi- tions that induce limb movements and trigger arousals from sleep (Decker et al., 2000). In addition, bilaterally administered intrastriatal 6-OHDA disrupts endogenous circadian rhythm in mice (Masini et al., 2017). Altogether, these behavioral findings further support the applicability of nigrostriatal 6-OHDA lesion in modeling PD-related sleep disorders.

In conclusion, this study shows that the partial unilateral striatal 6-OHDA lesion altered brain FC patterns when rats were in a urethane-induced REM-like sleep state. Therefore, the present model can serve as a valid tool to investigate the REM-sleep associated disorders characteristic of early PD.

\section{References}

Bargiotas P, Schuepbach MWM, Bassetti CL (2016) Sleep-wake disturbances in the premotor and early stage of Parkinson's disease. Curr Opin Neurol 29:763-772. CrossRef Medline

Biswal B, Yetkin FZ, Haughton VM, Hyde JS (1995) Functional connectivity in the motor cortex of resting human brain using echo-planar MRI. Magn Reson Med 34:537-541. CrossRef Medline

Blandini F, Nappi G, Tassorelli C, Martignoni E (2000) Functional changes of the basal ganglia circuitry in Parkinson's disease. Prog Neurobiol 62:63-88. CrossRef Medline

Bové J, Perier C (2012) Neurotoxin-based models of Parkinson's disease. Neuroscience 211:51-76. CrossRef Medline

Centonze D, Gubellini P, Picconi B, Calabresi P, Giacomini P, Bernardi $G$ (1999) Unilateral dopamine denervation blocks corticostriatal LTP. J Neurophysiol 82:3575-3579. CrossRef Medline

Chassain C, Bielicki G, Durand E, Lolignier S, Essafi F, Traoré A, Durif F (2008) Metabolic changes detected by proton magnetic resonance spectroscopy in vivo and in vitro in a murin model of Parkinson's disease, the MPTP-intoxicated mouse. J Neurochem 105:874-882. CrossRef Medline

Chung SJ, Lee Y, Lee JJ, Lee PH, Sohn YH (2017) Rapid eye movement sleep behaviour disorder and striatal dopamine depletion in patients with Parkinson's disease. Eur J Neurol 24:13141319. CrossRef Medline

Clement EA, Richard A, Thwaites M, Ailon J, Peters S, Dickson CT (2008) Cyclic and sleep-like spontaneous alternations of brain state under urethane anaesthesia. PLoS One 3:e2004. CrossRef Medline

Dayan E, Browner N (2017) Alterations in striato-thalamo-pallidal intrinsic functional connectivity as a prodrome of Parkinson's disease. Neuroimage Clin 16:313-318. CrossRef Medline

Decker MJ, Keating GL, Freeman AA, Rye DB (2000) Parkinsonianlike sleep-wake architecture in rats with bilateral striatal 6-OHDA lesions. Soc Neurosci Abstr 26:566.6.

DeLong MR, Wichmann T (2007) Circuits and circuit disorders of the basal ganglia. Arch Neurol 64:20-24. CrossRef Medline

Eckert T, Peschel T, Heinze HJ, Rotte M (2006) Increased pre-SMA activation in early PD patients during simple self-initiated hand movements. J Neurol 253:199-207. CrossRef Medline

Ellmore TM, Castriotta RJ, Hendley KL, Aalbers BM, Furr-Stimming E, Hood AJ, Suescun J, Beurlot MR, Hendley RT, Schiess MC (2013) Altered nigrostriatal and nigrocortical functional connectivity in rapid eye movement sleep behavior disorder. Sleep 36:18851892. CrossRef Medline

Emir UE, Tuite PJ, Öz G (2012) Elevated pontine and putamenal GABA levels in mild-moderate Parkinson disease detected by 7 tesla proton MRS. PLoS One 7:e30918. CrossRef Medline

Franzini C (1992) Brain metabolism and blood flow during sleep. $J$ Sleep Res 1:3-16. CrossRef

French IT, Muthusamy KA (2016) A review of sleep and its disorders in patients with Parkinson's disease in relation to various brain structures. Front Aging Neurosci 8:1-17. CrossRef Medline 
Gretenkord S, Rees A, Whittington MA, Gartside SE, LeBeau FEN (2016) Dorsal versus ventral differences in fast up-state associated oscillations in the medial prefrontal cortex (mPFC) of the urethane anaesthetised rat. J Neurophysiol 117:1126-1142. CrossRef Medline

Hacker CD, Perlmutter JS, Criswell SR, Ances BM, Snyder AZ (2012) Resting state functional connectivity of the striatum in Parkinson's disease. Brain 135:3699-3711. CrossRef Medline

Hara K, Harris RA (2002) The anesthetic mechanism of urethane: the effects on neurotransmitter-gated ion channels. Anesth Analg 94: 313-318. CrossRef Medline

Hauer BE, Negash B, Chan K, Vuong W, Colbourne F, Pagliardini S, Dickson CT (2018) Hyperoxia enhances slow-wave forebrain states in urethane anesthetized and naturally sleeping rats. J Neurophysiol 120:1505-1515. CrossRef Medline

Heller J, Brcina N, Dogan I, Holtbernd F, Romanzetti S, Schulz JB, Schiefer J, Reetz K (2017) Brain imaging findings in idiopathic REM sleep behavior disorder (RBD): a systematic review on potential biomarkers for neurodegeneration. Sleep Med Rev 34:23-33. CrossRef Medline

Janssen ML, Zwartjes DGM, Tan SKH, Vlamings R, Jahanshahi A, Heida T, Hoogland G, Steinbusch HWM, Visser-Vandewalle V, Temel $Y$ (2012) Mild dopaminergic lesions are accompanied by robust changes in subthalamic nucleus activity. Neurosci Lett 508:101-105. CrossRef Medline

Kääriäinen TM, Lehtonen M, Forsberg MM, Savolainen J, Käenmäki M, Männistö PT (2008) Comparison of the effects of deramciclane, ritanserin and buspirone on extracellular dopamine and its metabolites in striatum and nucleus accumbens of freely moving rats. Basic Clin Pharmacol Toxicol 102:50-58. CrossRef Medline

Kerr KM, Agster KL, Furtak SC, Burwell RD (2007) Functional neuroanatomy of the parahippocampal region: the lateral and medial entorhinal areas. Hippocampus 17:697-708. CrossRef Medline

Kickler N, Krack P, Fraix V, Lebas J-F, Lamalle L, Durif F, Krainik A, Rémy C, Segebarth C, Pollak P (2007) Glutamate measurement in Parkinson's disease using MRS at 3 T field strength. NMR Biomed 20:757-762. CrossRef Medline

Kish SJ, Rajput A, Gilbert J, Rozdilsky B, Chang LJ, Shannak K, Hornykiewicz O (1986) Elevated gamma-aminobutyric acid level in striatal but not extrastriatal brain regions in Parkinson's disease: correlation with striatal dopamine loss. Ann Neurol 20:26-31. CrossRef Medline

Lanciego JL, Luquin N, Obeso JA (2012) Functional neuroanatomy of the basal ganglia. Cold Spring Harb Perspect Med 2:a009621. CrossRef Medline

Lee CS, Sauer H, Björklund A (1996) Dopaminergic neuronal degeneration and motor impairments following axon terminal lesion by intrastriatal 6-hydroxydopamine in the rat. Neuroscience 72:641653. CrossRef Medline

Leikas JV, Kääriäinen TM, Jalkanen AJ, Lehtonen M, Rantamäki T, Forsberg MM (2017) Combined ipsilateral limb use score as an index of motor deficits and neurorestoration in parkinsonian rats. $J$ Neurosci Res 95:1858-1870. CrossRef Medline

Lenzi P, Zoccoli G, Walker AM, Franzini C (2000) Cerebral circulation in REM sleep: is oxygen a main regulating factor? Sleep Res Online 3:77-85. CrossRef Medline

Lima MMS, Andersen ML, Reksidler AB, Vital MABF, Tufik S (2007) The role of the substantia nigra pars compacta in regulating sleep patterns in rats. PLoS One 2:e513. CrossRef Medline

Lopes R, Delmaire C, Defebvre L, Moonen AJ, Duits AA, Hofman P, Leentjens AFG, Dujardin K (2016) Cognitive phenotypes in Parkinson's disease differ in terms of brain-network organization and connectivity. Hum Brain Mapp 38:1604-1621. CrossRef Medline

Luo C, Song W, Chen Q, Zheng Z, Chen K, Cao B, Yang J, Li J, Huang X, Gong Q, Shang HF (2014) Reduced functional connectivity in early-stage drug-naive Parkinson's disease: a resting-state fMRI study. Neurobiol Aging 35:431-441. CrossRef Medline

Maggi CA, Meli A (1986) Suitability of urethane anesthesia for physiopharmacological investigations in various systems: Part 1. General considerations. Experientia 42:109-114. CrossRef Medline
Mallol R, Barrós-Loscertales A, López M, Belloch V, Parcet MA, Avila C (2007) Compensatory cortical mechanisms in Parkinson's disease evidenced with $\mathrm{FMRI}$ during the performance of pre-learned sequential movements. Brain Res 1147:265-271. CrossRef Medline

Masini D, Lopes-Aguiar C, Bonito-Oliva A, Papadia D, Andersson R, Fisahn A, Fisone G (2017) The histamine H3 receptor antagonist thioperamide rescues circadian rhythm and memory function in experimental parkinsonism. Transl Psychiatry 7:e1088. CrossRef Medline

Massimini M, Ferrarelli F, Murphy MJ, Huber R, Riedner BA, Casarotto S, Tononi G (2010) Cortical reactivity and effective connectivity during REM sleep in humans. Cogn Neurosci 1:176-183. CrossRef Medline

Monnot C, Zhang X, Nikkhou-Aski S, Damberg P, Svenningsson P (2017) Asymmetric dopaminergic degeneration and levodopa alter functional corticostriatal connectivity bilaterally in experimental parkinsonism. Exp Neurol 292:11-20. CrossRef Medline

More SV, Kumar H, Cho D-Y, Yun Y-S, Choi D-K (2016) ToxinInduced Experimental Models of Learning and Memory Impairment. Int J Mol Sci 17: pii: E1447 CrossRef Medline

Nandhagopal R, McKeown MJ, Stoessl AJ (2008) Functional imaging in Parkinson disease. Neurology 70:1478-1488. CrossRef Medline

Paasonen J, Salo RA, Shatillo A, Forsberg MM, Närväinen J, Huttunen JK, Gröhn O (2016) Comparison of seven different anesthesia protocols for nicotine pharmacologic magnetic resonance imaging in rat. Eur Neuropsychopharmacol 26:518-531. CrossRef Medline

Paasonen J, Stenroos P, Salo RA, Kiviniemi V, Gröhn O (2018) Functional connectivity under six anesthesia protocols and the awake condition in rat brain. Neuroimage 172:9-20. CrossRef Medline

Pagliardini S, Funk GD, Dickson CT (2013) Breathing and brain state: Urethane anesthesia as a model for natural sleep. Respir Physiol Neurobiol 188:324-332. CrossRef Medline

Pagliardini S, Greer JJ, Funk GD, Dickson CT (2012) Statedependent modulation of breathing in urethane-anesthetized rats. 32:11259-11270. CrossRef Medline

Paxinos G, Watson CD (2007) The rat brain in stereotaxic coordinates, Ed 6. London: Elsevier.

Penttinen AM, Suleymanova I, Albert K, Anttila J, Voutilainen $\mathrm{MH}$, Airavaara M (2016) Characterization of a new low-dose 6-hydroxydopamine model of Parkinson's disease in rat. J Neurosci Res 94:318-328. CrossRef Medline

Perlbarg V, Lambert J, Butler B, Felfli $M$, Valabrègue R, Privat $A$, Lehéricy S, Petiet A (2018) Alterations of the nigrostriatal pathway in a 6-OHDA rat model of Parkinson's disease evaluated with multimodal MRI. PLoS One 13:e0202597. CrossRef Medline

Postuma RB, Adler CH, Dugger BN, Hentz JG, Shill HA, DriverDunckley E, Sabbagh MN, Jacobson SA, Belden CM, Sue LI, Serrano G, Beach TG (2015) REM sleep behavior disorder and neuropathology in Parkinson's disease. Mov Disord 30:14131417. CrossRef Medline

Postuma RB, Gagnon J, Montplaisir J (2013) Rapid eye movement sleep behavior disorder as a biomarker for neurodegeneration: the past 10 years. Sleep Med 14:763-767. CrossRef Medline

Pringsheim T, Jette N, Frolkis A, Steeves TDL (2014) The prevalence of Parkinson's disease: a systematic review and meta-analysis. Mov Disord 29:1583-1590. CrossRef Medline

Przedbroski S, Leviver $\mathrm{M}$, Jiang $\mathrm{H}$, Ferreira $\mathrm{M}$, Jackson-Lewis $\mathrm{V}$, Donaldson D, Togasaki DM (1995) Dose-dependent lesions of the dopaminergic nigrostriatal pathway induced by intrastriatal injection of 6-hydroxydopamine. Neuroscience 67:631-647. CrossRef Medline

Sauer H, Oertel WH (1994) Progressive degeneration of nigrostriatal dopamine neurons following intrastriatal terminal lesions with 6-hydroxydopamine: a combined retrograde tracing and immunocytochemical study in the rat. Neuroscience 59:401-415. CrossRef Medline 
Schapira AHV (2009) Etiology and pathogenesis of Parkinson disease. Neurol Clin 27:583-603. CrossRef Medline

Sharman M, Valabregue R, Perlbarg V, Marrakchi-Kacem L, Vidailhet M, Benali H, Brice A, Lehéricy S (2013) Parkinson's disease patients show reduced cortical-subcortical sensorimotor connectivity. Mov Disord 28:447-454. CrossRef Medline

Steriade M, Hobson JA (1976) Neuronal activity during the sleepwaking cycle. Prog Neurobiol 6:157-376. CrossRef Medline

Szewczyk-Krolikowski K, Menke RAL, Rolinski M, Duff E, SalimiKhorshidi G, Filippini N, Zamboni G, Hu MTM, Mackay CE (2014) Functional connectivity in the basal ganglia network differentiates PD patients from controls. Neurology 83:208-214. CrossRef Medline

Tahmasian M, Eickhoff SB, Giehl K, Schwartz F, Herz DM, Drzezga A, van Eimeren T, Laird AR, Fox PT, Khazaie H, Zarei M, Eggers C, Eickhoff CR (2017) Resting-state functional reorganization in Parkinson's disease: an activation likelihood estimation metaanalysis. Cortex 92:119-138. CrossRef Medline

Tanaka Y, Niijima K, Mizuno Y, Yoshida M (1986) Changes in gamma-aminobutyrate, glutamate, aspartate, glycine, and taurine contents in the striatum after unilateral nigrostriatal lesions in rats. Exp Neurol 91:259-268. CrossRef Medline

Taylor-Robinson SD, Turjanski N, Bhattacharya S, Seery JP, Sargentoni J, Brooks DJ, Bryant DJ, Cox IJ (1999) A proton magnetic resonance spectroscopy study of the striatum and cerebral cortex in Parkinson's disease. Metab Brain Dis 14:45-55. CrossRef Medline
Titova N, Chaudhuri KR (2017) Nonmotor Parkinson's and future directions, Ed 1. Cambridge, MA: Elsevier.

Vo Q, Gilmour TP, Venkiteswaran K, Fang J, Subramanian T (2014) Polysomnographic features of sleep disturbances and rem sleep behavior disorder in the unilateral 6-OHDA lesioned hemiparkinsonian rat. Parkinsons Dis 2014:852965. CrossRef Medline

Westphal R, Simmons C, Mesquita MB, Wood TC, Williams SCR, Vernon AC, Cash D (2017) Characterization of the resting-state brain network topology in the 6-hydroxydopamine rat model of Parkinson's disease. PLoS One 12:e0172394. CrossRef Medline

Whitten TA, Martz LJ, Guico A, Gervais N, Dickson CT (2009) Heat Synch: inter- and independence of body-temperature fluctuations and brain-state alternations in urethane-anesthetized rats. J Neurophysiol 102:1647-1656. CrossRef Medline

Wilson DA, Hoptman MJ, Gerum SV, Guilfoyle DN (2011) Statedependent functional connectivity of rat olfactory system assessed by fMRI. Neurosci Lett 497:69-73. CrossRef Medline

Wilson DA, Yan X (2010) Sleep-like states modulate functional connectivity in the rat olfactory system. J Neurophysiol 104:32313239. CrossRef Medline

Yuan H, Sarre S, Ebinger G, Michotte Y (2005) Histological, behavioural and neurochemical evaluation of medial forebrain bundle and striatal 6-OHDA lesions as rat models of Parkinson's disease. J Neurosci Methods 144:35-45. CrossRef Medline

Zhurakovskaya E, Paasonen J, Shatillo A, Lipponen A, Salo R, Aliev R, Tanila H, Gröhn O (2016) Global functional connectivity differences between sleep-like states in urethane anesthetized rats measured by fMRI. PLoS One 11:e0155343. CrossRef Medline 